\title{
U⿱宀⿻三丨口
}

\section{Application of remote sensing for automated litter detection and management}

Hamill, M., Magee, B., \& Millar, P. (2019). Application of remote sensing for automated litter detection and management. In S. Kapoor, \& K. Arai (Eds.), Advances in Computer Vision - Proceedings of the 2019 Computer Vision Conference CVC: Proceedings of the 2019 Computer Vision Conference (CVC), Volume 2 (Vol. 944, pp. 157-168). (Advances in Intelligent Systems and Computing). Springer International Publishing.

https://doi.org/10.1007/978-3-030-17798-0_15

Link to publication record in Ulster University Research Portal

Published in:

Advances in Computer Vision - Proceedings of the 2019 Computer Vision Conference CVC

Publication Status:

Published online: 24/04/2019

DOI:

10.1007/978-3-030-17798-0_15

\section{Document Version}

Author Accepted version

\section{General rights}

Copyright for the publications made accessible via Ulster University's Research Portal is retained by the author(s) and / or other copyright owners and it is a condition of accessing these publications that users recognise and abide by the legal requirements associated with these rights.

\section{Take down policy}

The Research Portal is Ulster University's institutional repository that provides access to Ulster's research outputs. Every effort has been made to ensure that content in the Research Portal does not infringe any person's rights, or applicable UK laws. If you discover content in the Research Portal that you believe breaches copyright or violates any law, please contact pure-support@ulster.ac.uk. 


\title{
Application of remote sensing for automated litter detection and management
}

\author{
Mark Hamill, Bryan Magee and Phillip Millar \\ Built Environment Research Institute, Ulster University, Shore Road, County Antrim, \\ BT37 OQB, Northern Ireland.
}

\begin{abstract}
The Clean Europe Network (CEN) estimates that cleaning litter in the EU accounts for $€ 10-13$ billion of public expenditure every year. The annual budget for managing roadside litter alone, is approximately $€ 1$ billion. While local authorities in Northern Ireland and elsewhere have legal requirements to monitor and control litter levels, requirements for compliance are unclear and frequently ignored. Against this background, the overall objective of this research is to develop an integrated management system allowing remote discrimination and quantification of roadside litter. As such, the intention is that local authorities can more effectively meet their statutory requirements with regards to litter management. The research aligns with objectives outlined by the UK Government and CEN in terms of improving litter-related data levels. As plastic containers of type RIC1, Polyethylene terephthalate (PETE), represent one of the most common components of roadside litter, its identification in the natural environment via remote sensing is a key objective. By combining published US Hyperspectral library data and experimental field study results, the initial findings of this research indicate that it is possible to discriminate PETE plastic samples in a grass background using a low-cost multispectral sensor primarily designed for agricultural use. While at an initial phase, the research presented has the potential to have a significant impact on the economic, environmental and statutory implications of roadside litter management. Future work will employ image processing and machine learning techniques to deliver a methodology for automatic identification and quantification of multiple roadside litter types.
\end{abstract}

Keywords: Image analysis, Multispectral, Litter, Remote sensing, Hyperspectral signatures.

\section{Introduction}

Local environmental charity Keep Northern Ireland Beautiful calculated in 2014 that the average cost to ratepayers for cleaning streets was $£ 38 \mathrm{M}$ per year [1]. The organisation stated that $97 \%$ of streets in Northern Ireland are littered and recognised plastic litter as a particular issue. The UK Government's primary recommendation [2] relating to litter is that more and better data is required to underpin more accurate management of its collection. Collation of roadside litter data by quantity, type and location is seen as a key component of this recommendation. The widespread physical, environmental and financial impact of littering is well accepted [3] and its monitoring and management is a statutory duty of all UK local authorities. However, requirements for compliance under statutory documents such as the Litter (Northern Ireland) Order 1994 are unclear and, as a result, frequently ignored. 
Of particular concern, plastic littering has reached such an extent worldwide that it has been recognised an indicator of a distinct geologic era [4]. In the US, for example, plastic litter has increased by $165 \%$ since 1969 and according to several studies [4-11], polyethylene terephthalate (PETE) - widely utilised in the food and drink industry - is by far the most common type of discarded plastic product. This plastic is internationally categorised using the Resin Coding Method [12] as Resin Identification Code (RIC) Type 1. Concern surrounding the impact and persistence of plastic litter $[5,6]$ has generated much research in measuring litter levels in the marine environment. However, despite the terrestrial origin of much plastic litter $[7,8]$, there appears to be little similar roadside- or built environment-based research.

Measurement of environmental plastic is currently carried out by physical observation, although there have been some attempts to utilise remote sensing. Remote sensing is defined as the detection of reflected electromagnetic radiation emanating from a surface using a wide range of imaging sensor types and imaging techniques such as sonar platforms and aerial cameras [13]. In the past decade, examples of remote sensing application in the built environment include identification of impervious surfaces to interpret urbanisation levels [14] and road centerline extraction in support of autonomous driving [15]. Vehicle mounted remote sensing has been successfully deployed to monitor road surface conditions [16]; work that has successfully demonstrated that deterioration of street furniture and road surfaces can be captured in urban environments to high levels of geo-spatial accuracy using vehicle-based sensors. Several other publications consider remote sensing in relation to road surface features and road surface conditions [17] and general sensing of urban surfce features [18]. However, the techniques reported have yet to be applied to the challenge of remote sensing of litter on urban and rural road networks.

Two types of remote sensor are principally used to detect reflectance spectra; namely multispectral (MS) and hyperspectral (HS). MS sensors measure reflected energy in typically four or five discreet electromagnetic spectral bands in the green to infra-red range. HS sensors also detect reflectance in discreet contiguous bands, albeit over 200 or more. MS sensors have primarily been used for vegetation management [19] and weed monitoring [20]. While a few examples of MS sensors having been used for litter, and more specifically plastic debris [21], measurement exist in the literature, their focus has been on marine and beach litter [21-23]. In these instances, as the debris being detected is typically large and the background homogenous, debris quantities have been quantifiable by applying brightness thresholds to two-tone images. HS remote sensing has also been considered as a method of discriminating plastics in this environment, with related research [24,25] considering remote sensing of macro plastics in both visible (VIS) and short-wave infrared (SWIR) spectra. Current HS equipment is most effective in a controlled environment and is commercially deployed in litter recycling facilities to assist with sorting. Serranti et al. [26] first demonstrated effective use of HS reflectance sensing techniques to discriminate specific plastic resin types for litter sorting.

Against this background, the aim of this research is to evaluate the effectiveness of HS and MS sensors to identify RIC Type 1 litter in a roadside environment. The paper presents two distinct phases of research. Phase I initially analysed HS reflectance profiles held in existing data to compare spectral profiles of 
common built-environment materials, including RIC Type 1 plastic. HS signatures in four distinct spectral bands, corresponding to MS sensitivity, were examined and the corresponding reflectance compared. The intention was to examine whether sufficient spectral information was contained in these bands to uniquely distinguish materials. Phase II subsequently acquired field data using a commonly available, Parrot Sequoia MS sensor, with data obtained analysed against the Phase I data. The work reported is the first stage of a longitudinal study focused on developing an automated litter monitoring system capable of distinguishing and quantifying roadside litter by type, to assist local authorities meet statutory litter reporting and management.

\section{Phase I - Spectral Data Analysis}

The research in this section was undertaken to support a hypothesis that litter in the built environment can be remotely identified using a low-cost MS sensor. Data used in Phase I of the study was acquired from the ECOSTRESS Spectral library; a resource created and made freely available by the U.S. Jet Propulsion Laboratory [27]. The library (formally the ASTER spectral library) [28], version 1.0 of which was released in February 2018, comprises more than 2,800 reflective spectra of natural and manmade materials. Spectra in the range $0.4-2.5 \mu \mathrm{m}$ was used for this study, corresponding to the spectral range of the multispectral sensor employed in Phase II $(0.53-0.81 \mu \mathrm{m})$. Sampling intervals of 0.001 and $0.004 \mu \mathrm{m}$ were considered in the 0.4-0.8 and 0.8-2.5 $\mu \mathrm{m}$ ranges respectively. Two spectral samples each, for two common European grasses, Avena fatua and Bromus Diandrus [29], were initially considered (see Figure 1a)). Clearly, a simple visual comparison of these profiles indicates a high degree of consistency across the spectrum considered, with strong distinguishing characteristics at several wavelengths.

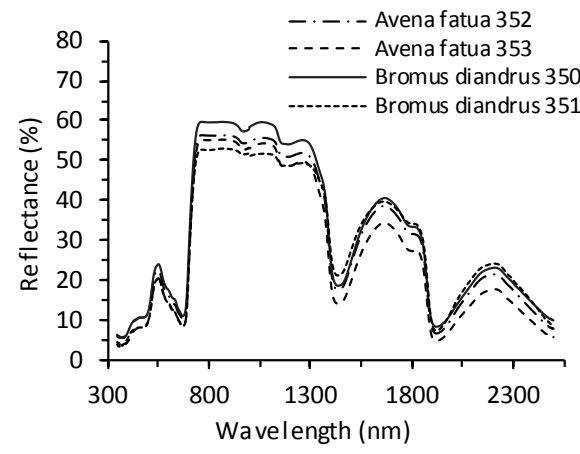

a)

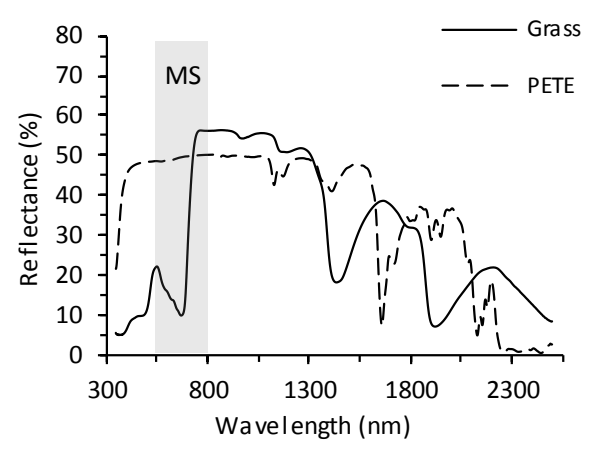

b)

Fig. 1. Comparative HS profiles for: a) common European grasses, and b) average value for grass plotted in comparison with PETE (MS spectral range superimposed)

As shown in Figure 1b), an averaged grass reflectance profile was then compared to that for PETE. Examination in the MS range $(525-800 \mathrm{~nm})$, indicates clear 
differentiation between profiles in most regions. While the profiles cross at $725 \mathrm{~nm}$ and show on $5 \%$ reflectance differences in the wavelength range $725-800 \mathrm{~nm}$, in the 500 $700 \mathrm{~nm}$ range, reflectance diverges significantly, with an average difference of more than $30 \%$. To analyse the unique nature of these spectral profiles more closely in the MS range, specific spectral band ranges corresponding to the capabilities of the MS sensor used in Phase II were then compared. As shown in Figure 2a) the discreet bands considered were: 1 . Green spectrum (530-570 nm); 2. Red spectrum (640-680 nm); 3 . Red Edge spectrum (725-745 nm); and 4. Near Infrared spectrum (770-810 nm).

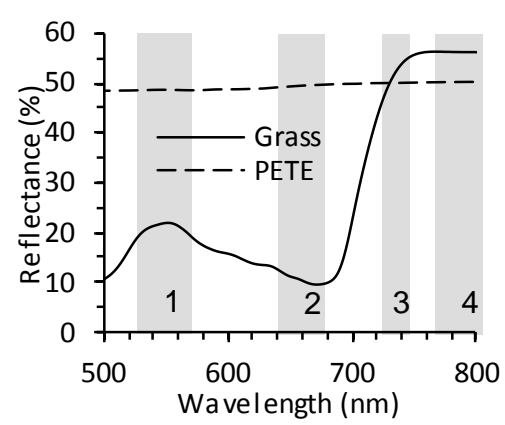

a)

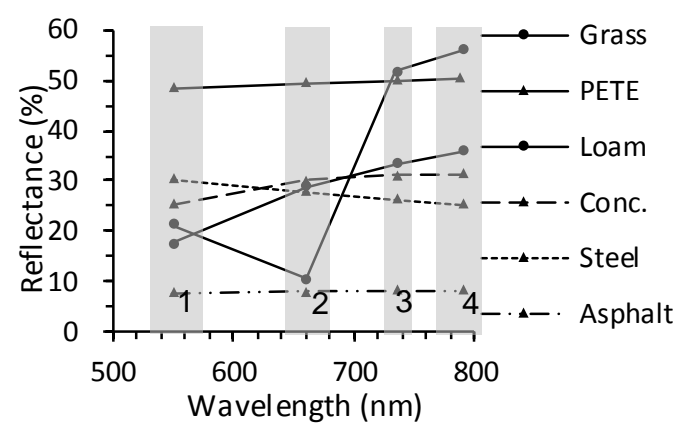

b)

Fig. 2. HS profiles in the 525-800 nm range with: a) all data points plotted for grass and PETE, and $b$ ) averaged data points across bands 1-4 plotted for grass and PETE in comparison to other common built-environment materials

When comparing PETE to grass across the 525-800 $\mathrm{nm}$ spectral range, unique profiles are apparent, with average differences in reflectance of +27.5 and $+38.7 \%$ in bands 1 and 2 respectively. In bands 3 and 4, the profiles converged, with PETE having slightly lower average reflectance values compared to grass (-1.6 and $-5.8 \%$ respectively). While the strongest distinction between the two materials is in bands 1 and 2 , it is recognised that the distinctive crossover in reflectance in bands 3-4 might play an important role in distinguishing the materials. As shown in Figure 2b), this work was extended to compare the reflectance signature of PETE against other materials commonly found in the roadside environment. In this instance, average reflectance values from the ECOSTRESS library were calculated for each material across band widths $1-4$.

Clearly from both figures $2 a$ ) and b), distinct characteristics of reflectance profiles across each band range were apparent for the materials considered. This finding provided support for the research hypothesis and confirmed potential for creating numeric material 'fingerprints' based on data considered across MS bands. Against this background, it was decided that the work should progress utilising MS field-captured sensor data to explore these characteristics further. 


\section{Phase II - Multispectral Sensor Reflectance Analysis}

The equipment used for the MS research was a Parrot Sequoia manufactured by Parrot SAS, France, comprising both sunshine and multispectral sensors. The equipment contained a 16 MP RGB camera with $63.9^{\circ}$ x 50.1 field of view (FOV) and four global shutters, 1.2 MP single-band cameras with $61.9^{\circ} \mathrm{x} 48.5^{\circ} \mathrm{FOV}$. The assembly was installed in a modified GoPro Hero5 mount with power was supplied by a 5V, 3A USB battery and supported by firmware version v.1.4.1.
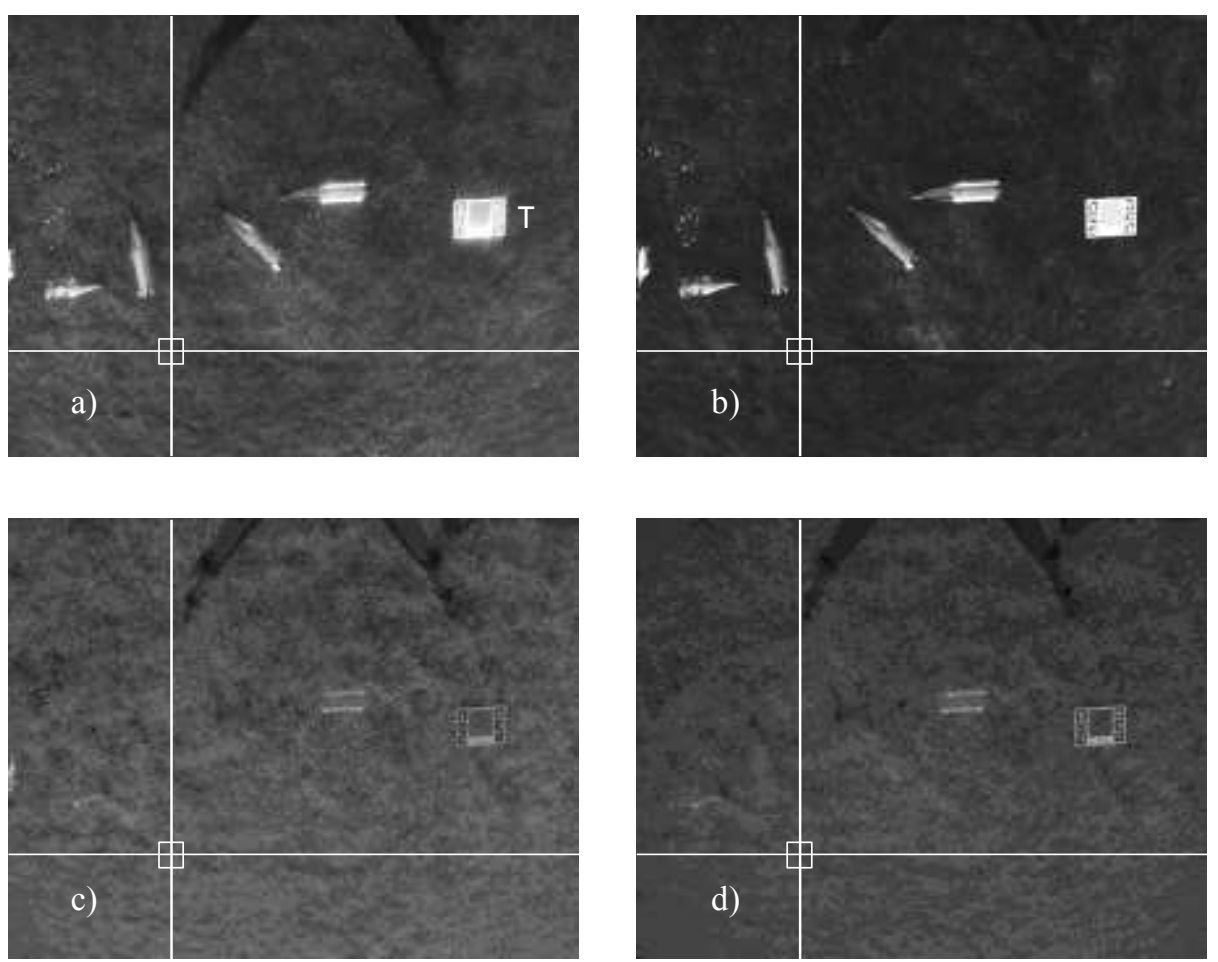

Fig. 3. Sequoia MS captures showing PETE plastic bottles on lawn grass indicating a typical sample point on each frame for: a) Green, b) Red, c) IR Edge \& d) Near-infrared spectrums

Calibration required the conversion of unprocessed image data to at-sensor radiance values via a linear correlation. No atmospheric corrections were required as the sensor was mounted close to the ground with atmospheric effects deemed negligible [30]. The sensor was mounted on a tripod with the lens assembly normal to the ground surface to reduce distortion and set at a height of $1,200 \mathrm{~mm}$; the minimum focus distance. A sample of calibration images is presented in Figure 3. Each field survey undertaken commenced with radiometric calibration using a standard Sequoia reference target, labeled ' $\mathrm{T}$ ' (Figure 3a)). This procedure generated reference data for subsequent numerical adjustments or image manipulations to compensate for variations in band sensitivity. 


\subsection{Image analysis}

The Parrott Sequoia MS sensor generated four, 1280 x 960 pixel greyscale images; one for each spectral band. These images were in 8-bit integer jpeg format giving a range of possible values from 0 to 255 for each pixel, where zero is black and 255 white. For image analysis the GNU Image Manipulation Program (GIMP) was used to capture, report and analyse image pixel values. The software reported pixel values in HSV format where $\mathrm{V}$ is a brightness value in the range 0-100. The software contained the appropriate tools to extract individual or sample averaged pixel values. The process allowed reliable and repeatable selection of discrete areas of images and contained tools to allow averaged pixel values to be determined from user-definable kernels. Each image band was separately calibrated to compensate for differing responses in each band. To do this, the reflectance value for the standard grey target was corrected to a reference value of $50 \%$. Three sample points for each grey target were captured using an averaged 10x10 pixel kernel. Table 1 presents a representative example of the sampling process.

Table 1. Example of spectral band reflectance value extraction for lawn grass

\begin{tabular}{|c|c|c|c|c|c|c|c|}
\hline Sample & $\begin{array}{c}\text { Image } \\
\text { Reference }\end{array}$ & $\begin{array}{c}\mathrm{X} \\
\text { Value }\end{array}$ & $\begin{array}{c}\text { Y } \\
\text { Value }\end{array}$ & R-Value & $\begin{array}{l}\text { Average } \\
\text { R-value }\end{array}$ & $\begin{array}{c}\text { Target } \\
\text { R-Value }\end{array}$ & $\begin{array}{c}\text { R-Value } \\
\text { Corr }\end{array}$ \\
\hline \multirow{12}{*}{$\begin{array}{l}\text { Lawn } \\
\text { Grass } \\
001\end{array}$} & \multirow{3}{*}{$\begin{array}{c}\text { 180312_165 } \\
\text { 336_0000_ } \\
\text { GRE }\end{array}$} & 600 & 450 & 34.4 & \multirow{3}{*}{37.0} & \multirow{3}{*}{74.9} & \multirow{3}{*}{24.7} \\
\hline & & 700 & 450 & 39.3 & & & \\
\hline & & 800 & 450 & 37.2 & & & \\
\hline & \multirow{3}{*}{$\begin{array}{c}\text { 180312_165 } \\
336 \_0000 \_ \\
\text {RED }\end{array}$} & 600 & 450 & 18.1 & \multirow{3}{*}{18.8} & \multirow{3}{*}{70.7} & \multirow{3}{*}{13.3} \\
\hline & & 700 & 450 & 20.6 & & & \\
\hline & & 800 & 450 & 17.7 & & & \\
\hline & \multirow{3}{*}{$\begin{array}{c}\text { 180312_165 } \\
\text { 336_0000_ } \\
\text { REG }\end{array}$} & 600 & 450 & 30.1 & \multirow{3}{*}{30.6} & \multirow{3}{*}{25.9} & \multirow{3}{*}{59.1} \\
\hline & & 700 & 450 & 30.2 & & & \\
\hline & & 800 & 450 & 31.6 & & & \\
\hline & \multirow{3}{*}{$\begin{array}{c}\text { 180312_165 } \\
336 \_0000 \_ \\
\text {NIR }\end{array}$} & 600 & 450 & 39.1 & \multirow{3}{*}{39.1} & \multirow{3}{*}{31.6} & \multirow{3}{*}{61.9} \\
\hline & & 700 & 450 & 38.8 & & & \\
\hline & & 800 & 450 & 39.4 & & & \\
\hline
\end{tabular}

Table 1 contains sample data from one set of four multispectral images from a single image capture event as illustrated in Figure 3. The four image references listed represent the Green, Red, Red-Edge and Near IR spectral bands (top to bottom). In this example, three reflectance measurements are presented for each. By using X and Y values to coordinate the sampling, consistency in sample areas across the spectral band images was effectively achieved. The sampling yielded corresponding reflectance R-values, which were averaged for each multispectral band. In this study, six grass samples and six PETE samples were acquired from five reference images, yielding 30 samples for both grass and PETE. A calibration reflectance measurement of the $50 \%$ grey calibration target was taken in each frame for the corresponding spectral band (recorded as Target $\mathrm{R}$-Value in Table 1). Radiometric calibration uses Target R-Value to harmonise the 
reflectance outputs to compensate for the differing sensitivities of the sensor bands as follows:

$$
R-\text { Value Corr }=\frac{50}{\text { Target } R-\text { value }} x \text { Average } R-\text { Value }
$$

The radiometrically correct reflectance values for the samples was calculated for the Average R Values and is shown in Table 1 as R-Value Corr. Data acquired from the sampling described above was then plotted to provide multispectral profiles as shown in Figure 4, which illustrates the distinct profiles for each material.

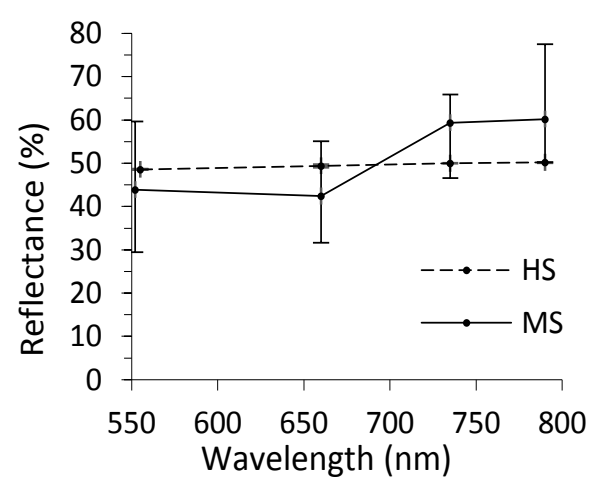

a)

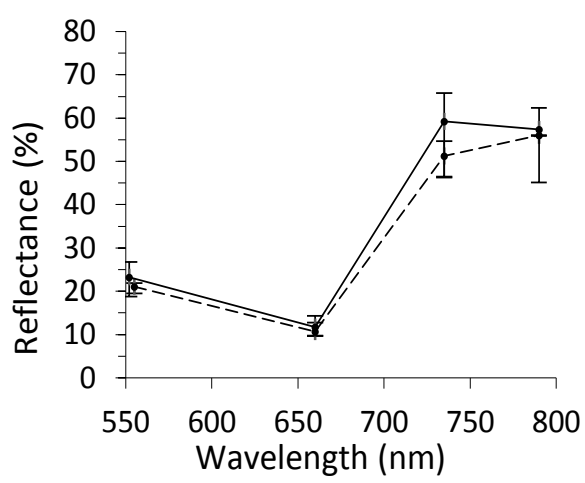

b)

Fig. 4. Comparisons of HS and MS spectral reflectance data for: a) PETE and b) grass

\subsection{Observations}

Figure 4 combines data recovered from the MS sample acquisition described above, compared against raw data from the ECOSTRESS HS library. Values for both PETE plastic and lawn grass were derived from the HS data as described in Section 2. The average reflectance values for MS and HS data are presented for both PETE and grass, with the reflectance range in each band being indicated by error bars. The profiles demonstrate that results obtained from the Parrott Sequoia MS sensor were generally as predicted, with a strong correlation between HS and MS reflectance data for both grass and PETE. It was expected that RIC1 plastic, which is optically clear, would transmit background reflectance information and the impact on reflectance profiles can be seen in Fig. 4a). The study clearly shows that Green and Red spectral bands provide clearest distinction between materials, IR Edge and Near IR the least. This is clearly observable in the grey-scale images in Figure 3, where PETE plastic bottles are visibly most transparent in the IR bands and least transparent in the visible bands. The narrow variance exhibited in the HS data compared to MS is indicative of the controlled conditions in which the HS data was captured; the HS reflectance being laboratory sampled against plain backgrounds. The wide variation seen in the MS PETE values is symptomatic of the reflective nature and curved surface of plastic bottles. With examples of these reflective highlights being most visible in Figures 3a) and b). 
Strong correlation between HS and MS profiles can be observed in all four bands for both materials. The average reflectance values acquired from the MS sensor field trials were in the ranges predicted by the analysis of the HS library data. Very little variation was witnessed in the reflectance values for the HS data, with less than $1 \%$ variation in any band for PETE and no more than $8 \%$ in any band for grass. This reflects the laboratory-based nature of the acquisition. MS reflectance values for grass showed good consistency in visible bands of no more than $8 \%$ and below $20 \%$ in the Infra-Red bands. MS reflectance data for PETE had acceptable variance, extending from just under $20 \%$ to $30 \%$. The MS reflectance profiles show that there is significant overlap in the IR bands, but despite some variance, no overlap exists in the visible bands. This is as predicted by the HS library data. It can be seen that again each material has a distinguishing, clearly recognisable profile capable of being 'fingerprinted' numerically.

Table 2. Numeric analysis of HS and MS fingerprints

\begin{tabular}{|c|c|c|c|c|}
\hline & \multicolumn{3}{|c|}{$\begin{array}{l}\text { Logical relationship between } \\
\text { spectral bands 1-4 }\end{array}$} & \multirow{2}{*}{$\begin{array}{c}\text { Then spectral } \\
\text { profile } \\
\text { equates to: }\end{array}$} \\
\hline & $\begin{array}{l}\text { IF 1:2 } \\
=\end{array}$ & $\begin{array}{l}\text { AND 2:3 } \\
=\end{array}$ & $\begin{array}{l}\text { AND 3:4 } \\
=\end{array}$ & \\
\hline \multirow{2}{*}{$\begin{array}{l}\text { PHASE I - Based on data } \\
\text { sourced from published } \\
\text { hyperspectral libraries }\end{array}$} & $\begin{array}{c}0.440- \\
0.654\end{array}$ & $\begin{array}{c}3.624- \\
5.663 \\
\end{array}$ & $\begin{array}{c}1.024- \\
1.212 \\
\end{array}$ & Grass \\
\hline & $\begin{array}{c}1.010- \\
1.023\end{array}$ & $\begin{array}{c}1.006- \\
1.018\end{array}$ & $\begin{array}{l}1.002- \\
1.005\end{array}$ & PETE \\
\hline \multirow{2}{*}{$\begin{array}{l}\text { PHASE II - Based on } \\
\text { experimental data } \\
\text { collected using } \\
\text { multispectral camera }\end{array}$} & $\begin{array}{c}0.365- \\
0.763\end{array}$ & $\begin{array}{c}3.239- \\
6.743 \\
\end{array}$ & $\begin{array}{c}0.685- \\
1.340\end{array}$ & Grass \\
\hline & $\begin{array}{c}0.531- \\
1.871\end{array}$ & $\begin{array}{c}0.845- \\
2.079\end{array}$ & $\begin{array}{l}0.762- \\
1.666\end{array}$ & PETE \\
\hline
\end{tabular}

Numeric analysis of reflectance data was undertaken as shown in Table 2, defined separately for both the HS and MS profiles. Profiling was based on a simple factoring of values between spectral bands to provide a series of numerical ratios. These ratios describe the mathematical relationship between the values in each band to each other for each material. The relationships are further described in terms of average multipliers and a range reflecting the measured reflectance from the experimental data.

This analysis provides a mathematical description of the reflectance curve for each material which has the potential to be used to identify and filter materials from their reflectance data using data-processing techniques. The IF:AND:AND relationship has been trialed in a spreadsheet matrix using 'fingerprints' for several ratios developed from the HS library data. Upper and lower reflectance values for selected common natural and manufactured materials have been used initially to develop a look-up table. A sample of this is presented in Table 3, in which sample values are entered and subjected to an IF:AND analysis in the form:

$$
\begin{aligned}
= & \mathrm{IF}((\mathrm{AND}(\mathrm{H} 13<\$ \mathrm{E} \$ 3, \mathrm{H} 13>\$ \mathrm{E} \$ 4, \mathrm{H} 14<\$ \mathrm{E} \$ 5, \mathrm{H} 14>\$ \mathrm{E} \$ 6, \mathrm{H} 15<\$ \mathrm{E} \$ 7, \\
& \mathrm{H} 15>\$ \mathrm{E} \$ 8, \mathrm{H} 16<\$ \mathrm{E} \$ 9, \mathrm{H} 16>\$ \mathrm{E} \$ 10)), " \mathrm{Y},, ")
\end{aligned}
$$


Where the sample values are within the reflectance range in all four bands for a given material in the library table a ' $\mathrm{Y}$ ' is shown in the results matrix. Where one or any of the values are beyond the upper and lower values, a null response is returned. The trial IF AND analysis demonstrates the potential of further work focused on automation of a numeric material 'fingerprinting' method.

Table 3. Sample of IF AND analysis using HS library data

\begin{tabular}{|c|c|c|c|c|c|c|c|c|}
\hline \multirow[b]{2}{*}{ Wavelength $(\mathrm{nm})$} & \multicolumn{8}{|c|}{ Spectral Reflectance Library } \\
\hline & $\begin{array}{c}\text { Oak } \\
\text { (fresh) }\end{array}$ & $\begin{array}{l}\text { Oak } \\
\text { (dry) }\end{array}$ & $\begin{array}{l}\text { Mixed } \\
\text { Spruce }\end{array}$ & $\begin{array}{c}\text { Meadow } \\
\text { Grass }\end{array}$ & $\begin{array}{l}\text { Lawn } \\
\text { Grass }\end{array}$ & $\begin{array}{c}\text { Grass } \\
\text { Dry }\end{array}$ & $\begin{array}{l}\text { HDPE } \\
\text { TransL }\end{array}$ & PETE \\
\hline Band 1 - 550 & 181.65 & 204.75 & 25.2 & 164.85 & 101.85 & 309.75 & 560.7 & 510.3 \\
\hline Range & 164.35 & 185.25 & 22.8 & 149.15 & 92.15 & 280.25 & 507.3 & 461.7 \\
\hline Band 2- 660 & 106.05 & 128.1 & 19.95 & 274.05 & 45.15 & 242.55 & 534.45 & 518.7 \\
\hline Range & 95.95 & 115.9 & 18.05 & 247.95 & 40.85 & 219.45 & 483.55 & 469.3 \\
\hline Band 3- 735 & 641.55 & 584.85 & 95.55 & 332.85 & 471.45 & 286.65 & 522.9 & 525 \\
\hline Range & 580.45 & 529.15 & 86.45 & 301.15 & 426.55 & 259.35 & 473.1 & 475 \\
\hline Band 4 - 790 & 874.65 & 689.85 & 130.2 & 365.4 & 724.5 & 309.75 & 516.6 & 527.1 \\
\hline \multirow[t]{2}{*}{ Range } & 791.35 & 624.15 & 117.8 & 330.6 & 655.5 & 280.25 & 467.4 & 476.9 \\
\hline & \multicolumn{8}{|c|}{ Sample values } \\
\hline Band 1 - 550 & 23 & 200 & 530 & 160 & 100 & 165 & 291 & 480 \\
\hline Band 2-660 & 19 & 120 & 520 & 250 & 42 & 100 & 230 & 480 \\
\hline Band 3- 735 & 87 & 530 & 480 & 300 & 430 & 600 & 263 & 480 \\
\hline \multirow[t]{2}{*}{ Band 4 - 790} & 120 & 625 & 470 & 335 & 660 & 800 & 285 & 480 \\
\hline & \multicolumn{8}{|c|}{ Results Matrix } \\
\hline Oak (fresh) & & & & null & & $\mathbf{Y}$ & & \\
\hline Oak (dry) & & $\mathbf{Y}$ & & & & & & \\
\hline Mixed Spruce & $\mathbf{Y}$ & & & & & & & \\
\hline \multicolumn{9}{|l|}{ Meadow Grass } \\
\hline Lawn Grass & & & & & $\mathbf{Y}$ & & & \\
\hline Grass Dry & & & & & & & $Y$ & \\
\hline HDPE TransL & & & $\mathbf{Y}$ & & & & & \\
\hline PETE & & & & & & & & $\mathbf{Y}$ \\
\hline
\end{tabular}

\section{Conclusion}

A simple and reliable method to distinguish PETE RIC Type 1 plastic in grassed areas, utilising inexpensive radiometric survey equipment has been demonstrated in this study. Under field conditions, the research indicates that different materials can be clearly discriminated in the Green and Red spectral bands. Nevertheless, there are some limitations that require deeper investigation and will form the basis of further research. For instance, the limited number of samples presented in this paper is recognised as a limiting factor and further study will address this. In addition, work will extend to collect data from other common materials. Future research will focus on methods such as using automated computer image processing. This will automatically measure and 
compare the reflectance values generated by the MS sensor allowing profiles for additional materials to be acquired more quickly. It was observed that the capture process benefited from a combination of bright and overcast conditions. Generally, for the trials undertaken, well-lit sunny or hazy but bright conditions were chosen. However, it was also observed that the quality of image capture in early morning or evening could be adversely affected due to low sun generating increased shadow; particularly where surfaces are undulating or uneven. Further trials will be carried out in a range of lighting conditions to establish the impact of these variations.

In terms of practical surveys, the effect of sensor movement on image acquisition quality will be evaluated. The Sequoia multispectral camera is principally designed for aerial drone surveys, where due to its elevation, large overlap between consecutive images exists and high frame rates are not required. The low sensitivity of the sensor means that capture rates up to two frames per second are attainable. Trials are planned to determine performance in vehicle mounted surveys.

Recognising that this is an early phase in the study, this paper presents an innovative method of litter detection in the built environment using remote sensing. This presents a potentially more economic and flexible solution to litter quantification and qualification than more expensive specialist solutions. The research indicates that in the area of remote sensing, it is possible to use a relatively simple multispectral sensor to distinguish materials. The research will continue with the final aim to develop an economic and reliable method of litter detection and measurement as part of an environmental monitoring scheme. It is anticipated that such a system will have a beneficial impact for those responsible for managing and maintaining the environment. A future phase of the research will involve field trials in collaboration with Mid and East Antrim District Council; a Northern Ireland local authority responsible for a district area of $1046 \mathrm{~km}^{2}$ comprising a network of major and minor roads. Field trials will initially take place on a representative section of trunk road with the intention of being extended as the project develops.

\section{References}

1. Allen, C. (2014) Northern Ireland Litter Survey 2014 [pdf] Keep Northern Ireland Beautiful. Available at <http://www.keepnorthernirelandbeautiful.org/keepnorthernirelandbeautiful/documents/00 6655.pdf $>$ [Accessed 13 April 2018]

2. Communities and Local Government Committee (2015) Litter and fly-tipping in England Seventh Report of Session 2014-15 [pdf] House of Commons Communities and Local Government Committee. Available at $<$ http://www. publications.parliament.uk/pa/cm201415/cmselect /cmcomloc/607/607.pdf> [Accessed 13 April 2018]

3. Clean Europe Network (2018), Facts and Costs [online] Available at: $<$ http://www. cleaneuropenetwork.eu/en/facts-and-costs/aup/> [Accessed 21 December 2018]

4. Zalasiewicz, J., Waters, C. N., Ivar do Sul, J. A., Corcoran, P. L., Barnosky, A D., Cearreta, A., Edgeworth, M., Gałuszka, A., Jeandel, C.. Leinfelder, R., McNeill, J.R., Steffen, W., Summerhayes, C., and Wagreich, M., (2016) The Geological Cycle of Plastics and Their 
Use as A Stratigraphic Indicator of The Anthropocene. Anthropocene. Vol.13, pp. 4-17, March 2016

5. Eriksen, M., Lebreton, L.C.M., Carson, H.S., Thiel, M., Moore, C.J., Borerro, J.C., Galgani F., Ryan P.G., \& Reisser J. (2014) Plastic Pollution in the World's Oceans: More Than 5 Trillion Plastic Pieces Weighing Over 250,000 Tons Afloat at Sea. PLoS ONE 9(12): e111913. https://doi.org/10.1371/journal.pone.0111913. December 2014

6. Andrady, A.L., (2015) Persistence of Plastic Litter in the Oceans. In: Bergmann M., Gutow L., Klages M. (eds) Marine Anthropogenic Litter. Springer, Cham, pp. 57 - 72, June 2015

7. Sherrington, C., (2016) Plastics in the Marine Environment. Eunomia [online] Available at: <https://www.eunomia.co.uk/reports-tools/plastics-in-the-marine-environment/> [Accessed 17 November 2018]

8. European Environment Agency (2017) Marine litter - a growing threat worldwide [pdf] European Environment Agency [online] < https://www.eea.europa.eu/highlights/marinelitter-2013-a-growing > [Accessed 17 November 2018]

9. Schultz, P.W. \& Stein, S.R., (2009) Executive Summary: Litter in America. - 2009 National litter research findings and recommendations. [pdf] Keep America Beautiful [online] Available at: 〈https://www.kab.org/news-info/research/litter-america-executive-summary> [Accessed 17 November 2018]

10. House of Commons Environmental Audit Committee (2017) Plastic bottles: Turning Back the Plastic Tide. First Report of Session 2017-19. HC 339 Published on 22 December 2017 by authority of the House of Commons.

11. Derrraik, J.G.B., (2002) The pollution of the marine environment by plastic debris: a review. Marine Pollution Bulletin 44 (2002) 842-852

12. ASTM International (2018) D7611/D7611M - 18, Standard Practice for Coding Plastic Manufactured Articles for Resin Identification [online] Available at:< https://compass.astm.org/EDIT/html_annot.cgi?D7611+18> [Accessed 28 Feb 2019]

13. Lillesand, T. M., Kiefer, R.W. and Chipman, J. W. (2015) Remote Sensing and Image Interpretation. 7th ed. New York: John Wiley \& Sons

14. Weng, Q., (2012), Remote Sensing of Impervious Surfaces in Urban Areas: Requirements, Methods, and Trends. Remote Sensing of Environment. Vol 117, pp. 34-49, February 2012.

15. Cheng, G., Wang, Y., Xu, S., Wang H. \& Xiang. S., (2017) Automatic Road Detection and Centerline Extraction via Cascaded End-to-End Convolutional Neural Network. IEEE Trans. on Geoscience and Remote Sensing. Vol 55, no. 6, pp. 3322-3337, June 2017.

16. Tadic, S., Favenza, A., Kavadias, C and Tsagaris. V. (2016) GHOST: A Novel Approach to Smart City Infrastructures Monitoring Through GNSS Precise Positioning. IEEE International Smart Cities Conference (ISC2). 12-15 September 2016. Trento, Italy

17. Vaa, T. (2013) Remote Sensing of Road Surface Conditions and intelligent transportation Systems Applications. In 20th ITS World Congress. 14-18 October 2017. Tokyo, Japan

18. Le Saux, B., Yokoya, N., Hansch, R. \& Prasad, S. (2018) Advanced Multisource Optical Remote Sensing for Urban Land Use and Land Cover Classification. IEEE Geoscience and Remote Sensing Magazine IEEE Geosci. Remote Sens. Mag. Geoscience and Remote Sensing Magazine, IEEE. 6(4):85-89 Dec, 2018

19. Berni, J. A. J., Zarco-Tejada, P. J., Suares-Barranco, M. D. \& Fereres-Castel, E., (2009) Thermal and Narrowband Multispectral Remote Sensing for Vegetation Monitoring From an Unmanned Aerial Vehicle in IEEE Transactions on Geoscience and Remote Sensing, Vol. 478, no 3, pp.722-738, March 2009.

20. Stroppiana, D., Villa, P. Sona, G., Ronchetti, G., Candiani, G., Pepe, M., Brusetto, L., Migliazzi, M. \& Boschetti, M., (2017) Early season weed mapping in rice crops using multispectral UAV data. International Journal of Remote Sensing. Received 31 Oct 2017, Accepted 05 Feb 2018, Published online: 21 Feb 2018 [online] Available at:< 
https://www.tandfonline.com/doi/abs/10.1080/01431161.2018.1441569?scroll=top\&journa 1Code $=$ tres20> [Accessed 04 March 2018]

21. Mitchell, K., Driedger, H.D. and Van Cappelin, P. (2013) Remote Sensing of Plastic Debris American Geophysical Union Science Policy Conference. Washington, D.C. USA, Volume: http://spc.agu.org/2013/eposters/eposter/o-05/ [online] Available at <https://www.researchgate.net/publication/242651084_Remote_Sensing_of_Plastic_Debri s> [Accessed 6 September 2018]

22. Nakashima, E., Isobe, A., Magome, Kako, S. and Deki, N. (2011) Using aerial photography and in situ measurements to estimate the quantity of macro-litter on beaches. Marine Pollution Bulletin 62(4) 762-769 [online] Available at <http://www.sciencedirect.com/science/article/pii/S0025326X11000105> [Accessed 20 June 2018]

23. Kako, S., Isobe, A. and Magome, S. (2010) Sequential monitoring of beach litter using webcams. Marine Pollution Bulletin 60(5) 775-779 [online] Available at <http://www.sciencedirect.com/science/ article/pii/S0025326X10000998> [Accessed 20 June 2018]

24. Goddijn-Murphy, L., Steef, P., Van Sebille, E., James, N. A. \& Gibb, S. (2018) Concept for a hyperspectral remote sensing algorithm for floating marine macro plastics. Marine Pollution Bulletin. Volume 126, January 2018, Pages 255-262

25. Asner, G., (2016). Workshop on mission concepts for marine debris sensing, January 1921,2016, east-west center of the university of Hawaii at Manoa, Honolulu, Hawaii.available at 〈http://iprc.soest.hawaii.edu/NASA_WS_MD2016/pdf/Asner2016.pdf〉, Accessed: 12 December 2018

26. Serranti, S, Gargiulo, A. \& Bonifazi, G. (2011) Characterization of post-consumer polyolefin wastes by hyperspectral imaging for quality control in recycling processes. Waste Management. Vol.31, Issue 11, pp. 2217-2227, November 2011.

27. Meerdink, S. K., Hook, S. J., Abbott, E.A., \& Roberts, D.A. (in prep). The ECOSTRESS Spectral Library 1.0. [online] Available at: $<$ https://speclib.jpl.nasa.gov/> [Accessed 4 March 2018]

28. Baldridge, A. M., Hook, S.J., Grove C.I. \& Rivera, G. (2008) The ASTER Spectral Library Version 2.0. Remote Sensing of Environment, Vol 113, pp. 711-715, November 2008.

29. Fitter, R., Fitter, F. \& Farrer, A., (1984) Collins guide to the grasses, sedges, rushes and ferns of Britain and Northern Europe. London: Collins

30. Karpouzli, E \& Malthus, T., (2003) The empirical line method for the atmospheric correction of IKONOS imagery. International Journal of Remote Sensing - INT J REMOTE SENS. 24. 1143-1150. 10.1080/0143116021000026779. 